Science, Technology and Development 34 (1): 35-40, 2015

ISSN 0254-6418 / DOI: 10.3923/std.2015.35.40

(c) 2015 Pakistan Council for Science and Technology

\title{
Genetic Variability in Eggplant for Agro-Morphological Traits
}

\author{
${ }^{2}$ Ihtizaz Hassan, ${ }^{1}$ Shakeel Ahmad Jatoi, ${ }^{1}$ Muhammad Arif, ${ }^{1}$ Sadar Uddin Siddiqui and ${ }^{1}$ Muhammad Ahson \\ ${ }^{1}$ Plant Genetic Resources Institute, National Agricultural Research Center, Islamabad, 45500, Pakistan \\ ${ }^{2}$ University College of Agriculture, University of Sargodha, Sargodha, Pakistan
}

\begin{abstract}
Eggplant is an important solanaceous plant cultivated world wide. Current study has been undertaken to characterize twenty two different Eggplant accessions for various agro-morphological traits at Plant Genetic Resources Institute, NARC, Islamabad. The study revealed an average to high variance for most of the parameters studied viz. Fruit weight, branching angle, days to flowering and plant height. However, low variance was observed for leaf lobation, petiole thickness, inter node length and number of flower (s) per axil. The relationship particularly among yield contributing traits was significant. Cluster analysis grouped the 22 Eggplant genotypes into three clusters and each cluster further sub-divided into two sub-clusters. The clustering pattern did not show any correspondence with the collection origin. The genotype 19326 remained outstanding in terms of better performance as compared to other genotypes studied. In general, the genotypes grouped in Cluster-I was tall statured having high mean values of different parameters and it were followed by cluster-II and III. The fruit shape and colour observed in the germplasm accessions was diverse ranging from round type to elongated and dark purple to white. However, predominant shape was round (40.9\%) type and purple (54\%). Although, the germplasm investigated comprised only 22 accessions, however, it revealed diverse pattern based on various traits. The information generated through this study will be helpful in devising future breeding programs in Eggplant.
\end{abstract}

Key words: Morphological, characterization, brinjal, eggplant, accessions

\section{INTRODUCTION}

Brinjal or eggplant (Solanum melongena L.) is an important non-tuberous member of Solanaceae family, native to Southern India, Its close relatives: S. aethiopicum (scarlet eggplant) and S. macrocarpon (Gboma eggplant) are of African origin. Eggplant is widely grown in America, Europe and Asia (Sekara et al., 2007). China is the leading country in eggplant annual production (539 million cwt) followed by India (232.4 million cwt), Egypt (27.1 million cwt), Turkey (18.6 million cwt), Indonesia (10.6 million cwt) and USA (1.4 million cwt) (Anonymous, 2012). According to Crop Reporting Services of Provinces in Pakistan, Eggplant is cultivated on an area of 9044 ha with the production of $89972 \mathrm{t}$ (Anonymous, 2010). It is available in the market throughout the year (Malik, 1994).

The global interest in development of cultivar has encouraged interest to the call for germplasm collection and preservation. An apparent priority can be recognized in the staple foods while it is difficult to ensure that valuable vegetable genetic resources are not lost because of their worldwide diversity of genera and species (George, 1989). Hence, these resources are of immense importance to plant breeders as reservoir of genetic variation. Characterization and evaluation of plant germplasm is imperative for categorization of germplasm and identification of desirable genotypes carried out in precision fields under sufficient growth and plant protection conditions for utilization in breeding programs (Upadhyaya et al., 2008).

South-east Asia region is being considered the primary diversification center of brinjal (Lester and Hassan, 1991). It is essential to collect data regarding the characteristics and variety of eggplant genetic resources for the sake of developing strong and effective eggplant breeding programmes (Sekara et al., 2007). While, it is impossible to identify a set of growth, floral and fruit characters for general characterization of brinjal due to high diversity in genus Solanum (Hazra et al., 2003; Daunay and Lester, 1989). Rodriguez-Burruezo et al. (2008) found that, in open field cultivation, using germplasm accessions as parents the resultant eggplant hybrids were competitive in production when compared with commercial hybrids. Furthermore, it also participates to boost up biodiversity.

Corresponding Author: Shakeel Ahmad Jatoi, Plant Genetic Resources Institute, National Agricultural Research Center, Islamabad, 45500, Pakistan 
Kumar et al. (2000) evaluated 28 lines and varieties of brinjal for 6 yield parameters and two qualitative characters i.e., colour and shape of fruit. Islam and Uddin (2009) performed the characterization of 16 genotypes of local and exotic germplasms of brinjal to study variation present among them. Chattopadhyay et al. (2011) performed characterization of thirty five diverse brinjal genotypes which showed highly significant variations among twelve quantitative traits. They recommended paying attention on selection based on marketable fruit weight and number of fruits per plant for yield improvement of brinjal. Javed et al. (2011) in his study found diversified response of different brinjal cultivars against brinjal shoot and fruit borer infestation.

Furini and Wunder (2004) morphologically characterized 94 Solanum accessions and found that morphological parameters were helpful in assessing similarities or differences among accessions. As a part of crop-improvement activity, a modest collection of genus 'Solanum' germplasm is being maintained at the Gene Bank, National Agricultural Research Centre, Pakistan. This germplasm is from local collection as well as exotic with little information on the level and kind of diversity present in the maintained collection. Hence, morphological characterization of these germplasm lines was considered an important area of study with the intention of their conservation and utilization in future. The present study also estimates the natural variation among these germplasm lines for utilization in breeding programmes.

\section{MATERIALS AND METHODS}

The present investigation was carried out in an augmented design at the field of Plant Genetic Resources Institute, National Agriculture Research Centre, Islamabad during 2012. In this study 22 different accessions of Eggplant (Solanum melongena) taken from Gene Bank, NARC were investigated for various agro-morphological characteristics (Table 1). The trait list was selected from "The Descriptors for Characterization and Evaluation in Plant Genetic Resources (Volume 2)" developed by National Institute of Agrobiological Resources, The Ministry of Agriculture, Forestry and Fisheries of Japan (Table 2). Nursery of Eggplant germplasm was raised in polythene tubes under glasshouse conditions. The seedlings were then transplanted on the ridges in the field keeping the plant to plant distance of $45-60 \mathrm{~cm}$. After checking the successful growth of plants, five plants were randomly selected from each accession and then tagged for data recording.

Statistical analysis: The quantitative data was subjected to statistical analyses including descriptive statistics, simple correlation coefficients and cluster analysis whereas the qualitative data was analyzed through frequency distribution. Among the multivariate analyses, cluster analysis was performed using numerical taxonomy based software NTSYS-pc (Numerical Taxonomy System, version 2.0; Rohlf, 2000).

Table 1: Passport information of the eggplant (Solanum melongena) germplasm investigated

\begin{tabular}{lll}
\hline Accession No. & Collection date & Origin/place of collection \\
\hline $19326-1$ & $26 / 10 / 2002$ & Punjab, Pakistan \\
18474 & $4 / 5 / 2000$ & Punjab, Pakistan \\
18479 & $4 / 5 / 2000$ & Punjab, Pakistan \\
9895 & $1 / 10 / 1987$ & KPK, Pakistan \\
20537 & $26 / 05 / 2003$ & KPK, Pakistan \\
White egg & $3 / 1 / 2003$ & Pakistan \\
20509 & $22 / 05 / 2003$ & KPK, Pakistan \\
$4729-1$ & $24 / 06 / 2004$ & Punjab, Pakistan \\
10926 & $10 / 5 / 2000$ & Punjab, Pakistan \\
18489 & $3 / 11 / 2000$ & AJK, Pakistan \\
25915 & $3 / 1 / 2003$ & Pakistan \\
10927 & $10 / 5 / 2000$ & Punjab, Pakistan \\
10854 & $6 / 5 / 2000$ & Punjab, Pakistan \\
25916 & $3 / 1 / 2003$ & Unknown \\
18481 & $29 / 04 / 2000$ & Punjab, Pakistan \\
19326 & $26 / 10 / 2002$ & Punjab, Pakistan \\
19502 & $24 / 4 / 2004$ & Unknown \\
$4736-16$ & $27 / 06 / 2004$ & Punjab, Pakistan \\
18473 & $4 / 5 / 2000$ & Punjab, Pakistan \\
BARI-1 & 2009 & Bangladesh \\
25919 & $23 / 10 / 2002$ & Punjab, Pakistan \\
19324 & $21 / 10 / 2002$ & Punjab, Pakistan
\end{tabular}


Sci. Technol. Dev., 34 (1): 35-40, 2015

Table 2: List of various parameters and measurement techniques used in this study

\begin{tabular}{ll}
\hline Parameters & Description \\
\hline Quantitative parameters & Measured in cm at the time of first flowering \\
Leaf length & Measured in cm at the time of first flowering \\
Leaf width & Measured in cm at the time of first flowering \\
Leaf lobation $(\mathrm{cm})$ & Measured in cm at the time of first flowering \\
Petiole length $(\mathrm{cm})$ & Measured in mm at the time of first flowering \\
Petiole thickness $(\mathrm{mm})$ & Measured in integer at the time of first flowering \\
Branching angle & Calculated from transplanting to first flowering \\
Days to flowering & Measured in cm at the time of first flowering \\
Height of the first inflorescence & Calculated at the time of first flowering \\
Number of flowers per axil & Measured in cm at commercial ripening stage \\
Mature fruit length & Measured in cm at commercial ripening stage \\
Diameter of mature fruit & Measured in grams at commercial ripening stage \\
Mature fruit weight & Measured in mm at commercial ripening stage \\
Peduncle thickness & Measured in cm at harvest time \\
Internode length & Measured in cm at harvest time \\
Plant height & Measured in mm at harvest time \\
Stem thickness & \\
Qualitative parameters & Observed at the time of first flowering (intermediate, slightly broad, broad, very broad) \\
Leaf shape & Observed at the time of first flowering (green, slightly green) \\
Leaf colour & Observed at the time of first flowering (slightly narrow, intermediate, slightly wide, wide) \\
Plant breadth & Observed at the time of first flowering (weak, slightly weak, intermediate, slightly strong, strong, very \\
Plant branching & strong, extremely strong) \\
& Observed at the time of first flowering (green, purple) \\
Stem colour & Observed at the time of first flowering (light purple, purple) \\
Flower colour & Measured at commercial ripening stage (round, egg-shaped, long egg-shaped, elongated) \\
Fruit shape & Measured at commercial ripening stage (white, green, purple red, purple black, dark purple black) \\
Fruit colour &
\end{tabular}

\section{RESULTS AND DISCUSSION}

Quantitative traits: Descriptive statistics of Eggplant genotypes displayed variability in different quantitative parameters evaluated (Table 3). Fruit weight remained the highly variable parameter among the 22 genotypes of eggplant investigated. It was observed that branching angle reflected high variance among the germplasm assayed and it ranged between $35.33^{\circ}$ (18489) to $86.33^{\circ}$ (10854). Plant height and number of days to flowering displayed moderate to high variability in Eggplant germplasm. Number of days to flowering exhibited high variability ranging from 44 days (19502) to 88 days (25915, 10927 and white egg). The variability observed in plant height ranged from $55 \mathrm{~cm}$ (20509) to $94 \mathrm{~cm}$ (25916, 18479).

Leaf length, leaf width, fruit length and fruit width showed medium to low variation among the germplasm accession studied. In a similar type of study parameters such as plant height and leaf size showed same results with the current study (Hazra et al., 2003). The variance observed for various traits in the genotype assayed could be used to establish groups in the present germplasm. For the traits like leaf lobation, petiole thickness, inter node length and number of flowers per axil a low genetic variability was observed which showed narrow genetic base of the germplasm investigated for these traits.

Qualitative traits: The frequency distribution pattern of qualitative characters in Eggplant showed diversified results (Table 4). The predominant leaf shape was broad (45.5\%) followed by slightly broad (27.3\%), Intermediate (22.7\%) and very broad (4.5\%). In the case of leaf colour, the percentage of green leaves is $54.5 \%$ and the rest genotypes had slightly dark green leaves. The pre-dominant flower colour was purple $(72.7 \%)$ and remaining had light purple flowers.

The plant breadth was intermediate (40.9\%) followed by slightly wide (36.4\%), wide (18.2\%) and slightly narrow (4.5\%) while in case of leaf plant branching, percentage of slightly weak branching habit and weak branching habit is equal (22.7\%) which is followed by strong plant branching (18.2\%), slightly strong and weak branching habit is also same (13.6\%) and an equal percentage was been observed in very strong and extremely strong branching habit (4.5\%). The percentage of green stem is $77.3 \%$ and the rest genotypes had purple stem.

The fruit shape was mostly round type (40.9\%) followed by elongated type (31.8\%), long egg shaped (18.2\%) and egg shaped (9.1\%) whereas the percentage of purple red and purple black colour fruit was equal i.e., $27.3 \%$ followed by green colour fruits $(22.7 \%)$, dark purple black (13.6\%) and white (9.1\%).

Trait association: The correlation coefficients displayed significant results for various quantitative traits (Table 5). Leaf parameters viz., leaf length, leaf width, leaf lobation, petiole length and petiole thickness revealed positive and highly significant correlation with each other which 
Sci. Technol. Dev., 34 (1): 35-40, 2015

Table 3: Descriptive statistics for various traits recorded in eggplant genotypes

\begin{tabular}{|c|c|c|c|c|c|}
\hline Parameters & Mean \pm SE & SD & Sample variance & Min. & Max. \\
\hline $\begin{array}{l}\text { Leaf length (cm) } \\
\text { (ctis }\end{array}$ & $14.90 \pm 1.12$ & 5.27 & 27.80 & 3.70 & 21.90 \\
\hline Leaf width (cm) & $11.31 \pm 0.84$ & 3.95 & 15.62 & 3.30 & 18.30 \\
\hline Leaf lobation (cm) & $2.64 \pm 0.20$ & 0.92 & 0.85 & 1.20 & 4.40 \\
\hline Petiole length $(\mathrm{cm})$ & $7.36 \pm 0.47$ & 2.20 & 4.82 & 2.90 & 10.61 \\
\hline Petiole thickness (mm) & $4.28 \pm 0.28$ & 1.32 & 1.73 & 1.92 & 6.71 \\
\hline Branching angle (Degree) & $57.62 \pm 3.26$ & 15.28 & 233.62 & 35.33 & 86.33 \\
\hline Internode length $(\mathrm{cm})$ & $6.77 \pm 0.22$ & 1.03 & 1.06 & 4.90 & 8.80 \\
\hline Plant height $(\mathrm{cm})$ & $75.00 \pm 2.19$ & 10.28 & 105.62 & 55.00 & 94.00 \\
\hline Stem thickness (mm) & $13.27 \pm 0.78$ & 3.65 & 13.33 & 6.64 & 20.85 \\
\hline Days to flowering (No) & $63.14 \pm 2.79$ & 13.07 & 170.89 & 44.00 & 88.00 \\
\hline Height of 1st inflorescence (cm) & $17.72 \pm 1.26$ & 5.89 & 34.72 & 6.60 & 29.90 \\
\hline No. of flowers per axil (No) & $3.27 \pm 0.37$ & 1.72 & 2.97 & 1.00 & 7.00 \\
\hline Mature fruit length $(\mathrm{cm})$ & $11.74 \pm 1.29$ & 6.07 & 36.88 & 1.80 & 22.90 \\
\hline Diameter of mature fruit $(\mathrm{cm})$ & $5.82 \pm 0.72$ & 3.40 & 11.54 & 1.30 & 12.40 \\
\hline Mature fruit weight (g) & $97.48 \pm 13.11$ & 61.50 & 3782.77 & 12.14 & 214.00 \\
\hline Peduncle thickness (mm) & $6.32 \pm 0.55$ & 2.59 & 6.69 & 1.56 & 9.67 \\
\hline
\end{tabular}

Table 4: Frequency distribution of qualitative traits in eggplant germplasm

\begin{tabular}{|c|c|c|}
\hline Explanation & Frequency & Percentage \\
\hline \multicolumn{3}{|l|}{ Leaf shape } \\
\hline Intermediate & 5 & 22.7 \\
\hline Slightly broad & 6 & 27.3 \\
\hline Broad & 10 & 45.5 \\
\hline Very broad & 1 & 4.5 \\
\hline \multicolumn{3}{|l|}{ Leaf colour } \\
\hline Green & 12 & 54.5 \\
\hline Slightly dark green & 10 & 45.5 \\
\hline \multicolumn{3}{|l|}{ Plant breadth } \\
\hline Slightly narrow & 1 & 4.5 \\
\hline Intermediate & 9 & 40.9 \\
\hline Slightly wide & 8 & 36.4 \\
\hline Wide & 4 & 18.2 \\
\hline \multicolumn{3}{|l|}{ Plant branching } \\
\hline Weak & 3 & 13.6 \\
\hline Slightly weak & 5 & 22.7 \\
\hline Intermediate & 5 & 22.7 \\
\hline Slightly strong & 3 & 13.6 \\
\hline Strong & 4 & 18.2 \\
\hline Very strong & 1 & 4.5 \\
\hline Extremely strong & 1 & 4.5 \\
\hline \multicolumn{3}{|l|}{ Stem colour } \\
\hline Green & 17 & 77.3 \\
\hline Purple & 5 & 22.7 \\
\hline \multicolumn{3}{|l|}{ Flower colour } \\
\hline Light purple & 6 & 27.3 \\
\hline Purple & 16 & 72.7 \\
\hline \multicolumn{3}{|l|}{ Fruit shape } \\
\hline Round & 9 & 40.9 \\
\hline Egg shaped & 2 & 9.1 \\
\hline Long egg shaped & 4 & 18.2 \\
\hline Elongated & 7 & 31.8 \\
\hline \multicolumn{3}{|l|}{ Fruit colour } \\
\hline White & 2 & 9.1 \\
\hline Green & 5 & 22.7 \\
\hline Purple red & 6 & 27.3 \\
\hline Purple black & 6 & 27.3 \\
\hline Dark purple black & 3 & 13.6 \\
\hline
\end{tabular}

means increase/decrease in one parameter will directly influence the increase/decrease in the other character. Leaf width also presented positive correlation with peduncle thickness.
Plant height significantly exhibited a positive trend with all leaf parameters except with leaf lobation. Plant height also showed positive correlation with stem thickness and diameter of mature fruit. Moreover, stem thickness showed substantially positive association with leaf length, leaf width, diameter of mature fruit, mature fruit weight and peduncle thickness. Height of first inflorescence had a considerable positive trend with leaf width, petiole length and days to flowering. Mature fruit weight and diameter of mature fruit also exhibited a highly significant positive correlation with each other. Similar results for fruit diameter and fruit weight were been observed in a recent study (Chattopadhyay et al., 2011). Relationship between leaf and fruit size was not significant in the current study that have already been found by a previous researcher (Hazra et al., 2003).

There was a highly significant and negative correlation between peduncle thickness and branching angle. Besides this number of flowers per axil presented a considerable negative trend with fruit diameter and fruit weight, which means more number of flowers per axil results in less fruit diameter and low fruit weight and less number of flowers per axil produce fruit with high diameter and more fruit weight.

Cluster analysis: Cluster analysis categorized 22 Eggplant genotypes into three main groups I, II and III (Fig. 1; Table 6). Group-I contained 8 accessions, group-II contained 9 genotypes whereas group-III comprised 5 genotypes. On the basis of Euclidean distance, Accessions 25919 and 19324 showed very close relationship with each other. Besides these accessions 20509 and 10854 were also found closely related with each other. BARI-1 (from Bangladesh) and White-egg (from Pakistan) also presented a significant association between both of the genotypes because of their mostly similar morphological characters.

Inter-cluster variation was estimated through combining the data set of each cluster separately which 
Sci. Technol. Dev., 34 (1): 35-40, 2015

Table 5: Comparison of correlation coefficients for different traits in eggplant germplasm

\begin{tabular}{|c|c|c|c|c|c|c|c|c|c|c|c|c|c|c|c|c|}
\hline Traits & & $\mathrm{LL}$ & LW & Llob & PL & $\mathrm{PT}$ & $\mathrm{BA}$ & IL & $\mathrm{PH}$ & ST & DTF & Hfln & Fl/Axl & MFL & DMF & MFW \\
\hline Leaf width (cm) & LW & 0.88 & & & & & & & & & & & & & & \\
\hline Leaf lobation (cm) & Llob & 0.72 & 0.88 & & & & & & & & & & & & & \\
\hline Petiole length (cm) & PL & 0.80 & 0.86 & 0.89 & & & & & & & & & & & & \\
\hline Petiole thickness (mm) & PT & 0.84 & 0.92 & 0.83 & 0.83 & & & & & & & & & & & \\
\hline Branching angle (degree) & BA & -0.17 & -0.22 & 0.06 & -0.08 & -0.16 & & & & & & & & & & \\
\hline Internode length $(\mathrm{cm})$ & IL & 0.06 & 0.02 & -0.03 & 0.00 & 0.16 & 0.02 & & & & & & & & & \\
\hline Plant height $(\mathrm{cm})$ & PH & 0.69 & 0.66 & 0.53 & 0.54 & 0.65 & -0.27 & 0.05 & & & & & & & & \\
\hline Stem thickness (mm) & ST & 0.63 & 0.58 & 0.34 & 0.37 & 0.51 & -0.53 & 0.04 & 0.77 & & & & & & & \\
\hline Days to flowering (No) & DTF & 0.01 & 0.07 & 0.26 & 0.42 & 0.14 & 0.19 & 0.25 & -0.23 & -0.41 & & & & & & \\
\hline $\begin{array}{l}\text { Height of the first } \\
\text { inflorescence }(\mathrm{cm})\end{array}$ & HFIN & 0.49 & 0.57 & 0.53 & 0.56 & 0.51 & -0.02 & 0.10 & 0.27 & 0.01 & 0.54 & & & & & \\
\hline No. of flowers per axil (No) & $\mathrm{Fl} / \mathrm{Axl}$ & 0.21 & 0.08 & 0.23 & 0.40 & 0.16 & 0.17 & -0.13 & -0.01 & -0.21 & 0.35 & 0.23 & & & & \\
\hline Mature fruit length (cn & MFL & 0.48 & 0.45 & 0.11 & 0.17 & 0.36 & -0.50 & -0.09 & 0.22 & 0.46 & -0.43 & 0.09 & -0.19 & & & \\
\hline Diameter of mature fruit $(\mathrm{cm})$ & DMF & 0.46 & 0.48 & 0.23 & 0.25 & 0.47 & -0.29 & 0.10 & 0.56 & 0.64 & -0.19 & 0.12 & -0.57 & 0.27 & & \\
\hline Mature fruit weight (g) & MFW & 0.51 & 0.51 & 0.18 & 0.21 & 0.47 & -0.30 & 0.06 & 0.45 & 0.60 & -0.36 & 0.08 & -0.54 & 0.58 & 0.90 & \\
\hline Peduncle thickness (mm) & PedT & 0.47 & 0.59 & 0.41 & 0.42 & 0.51 & -0.64 & 0.30 & 0.37 & 0.61 & -0.01 & 0.32 & -0.12 & 0.43 & 0.40 & 0.36 \\
\hline
\end{tabular}

$0.42-0.53 *$ Significant at 0.05 probability level, 0.54 and above **Significant at 0.01 probability level

Table 6: Clustering model of Solanum accessions into different clusters

\begin{tabular}{|c|c|c|c|}
\hline Cluster & Sub-clusters & $\begin{array}{l}\text { No. of } \\
\text { accessions }\end{array}$ & Accession No. \\
\hline \multirow[t]{2}{*}{1} & 1 & 3 & 19326, 18479, 25916 \\
\hline & 2 & 5 & $\begin{array}{l}\text { 18474, 4729-1, White-egg, BARI-1, } \\
25915\end{array}$ \\
\hline \multirow[t]{2}{*}{2} & 1 & 5 & $19326-1,18473,19502,25919,19324$ \\
\hline & 2 & 4 & 9895, 18481, 20537, 4736-16 \\
\hline \multirow[t]{2}{*}{3} & 1 & 3 & 20509, 10854, 10926 \\
\hline & 2 & 2 & 18489, 10927 \\
\hline
\end{tabular}

Table 7: Inter-cluster variation for various parameters in Solanum genotypes

\begin{tabular}{lccc}
\hline Parameters & Cluster 1 & Cluster 2 & Cluster 3 \\
\hline Leaf length & 19.65 & 15.13 & 6.90 \\
Leaf width & 15.18 & 10.63 & 6.34 \\
Leaf lobation & 3.63 & 2.12 & 2.02 \\
Petiole length & 9.66 & 6.40 & 5.38 \\
Petiole thickness & 5.56 & 4.06 & 2.60 \\
Branching angle & 58.26 & 50.11 & 70.34 \\
Internodal length & 6.97 & 6.77 & 6.46 \\
Plant height & 81.25 & 76.33 & 62.60 \\
Stem thickness & 15.27 & 14.17 & 8.44 \\
Days to flowering & 68.38 & 54.78 & 69.80 \\
Height of first inflorescence & 20.95 & 16.33 & 15.04 \\
Flowers per axil & 4.25 & 2.44 & 3.20 \\
Mature fruit length & 11.84 & 15.77 & 4.34 \\
Diameter of mature fruit & 6.32 & 7.18 & 2.59 \\
Mature fruit weight & 101.89 & 131.48 & 29.23 \\
Peduncle thickness & 7.93 & 6.42 & 3.55 \\
\hline
\end{tabular}

revealed useful information (Table 7). The genotypes denoting high mean values for different traits were grouped into cluster-I followed by cluster-II. Similarly the germplasm accessions with smaller mean values for different parameters were clustered together in cluster-III. Hence the lowest mean for all leaf parameters viz., leaf length, leaf width, leaf lobation, petiole length and petiole thickness were found in cluster- 3 while cluster- 1 has the highest (Table 7). Similarly, plant height and stem diameter also showed significant variation with maximum values exhibited by cluster 1 , followed by cluster 2 and cluster 3 . Number of days to flowering in cluster 1 and

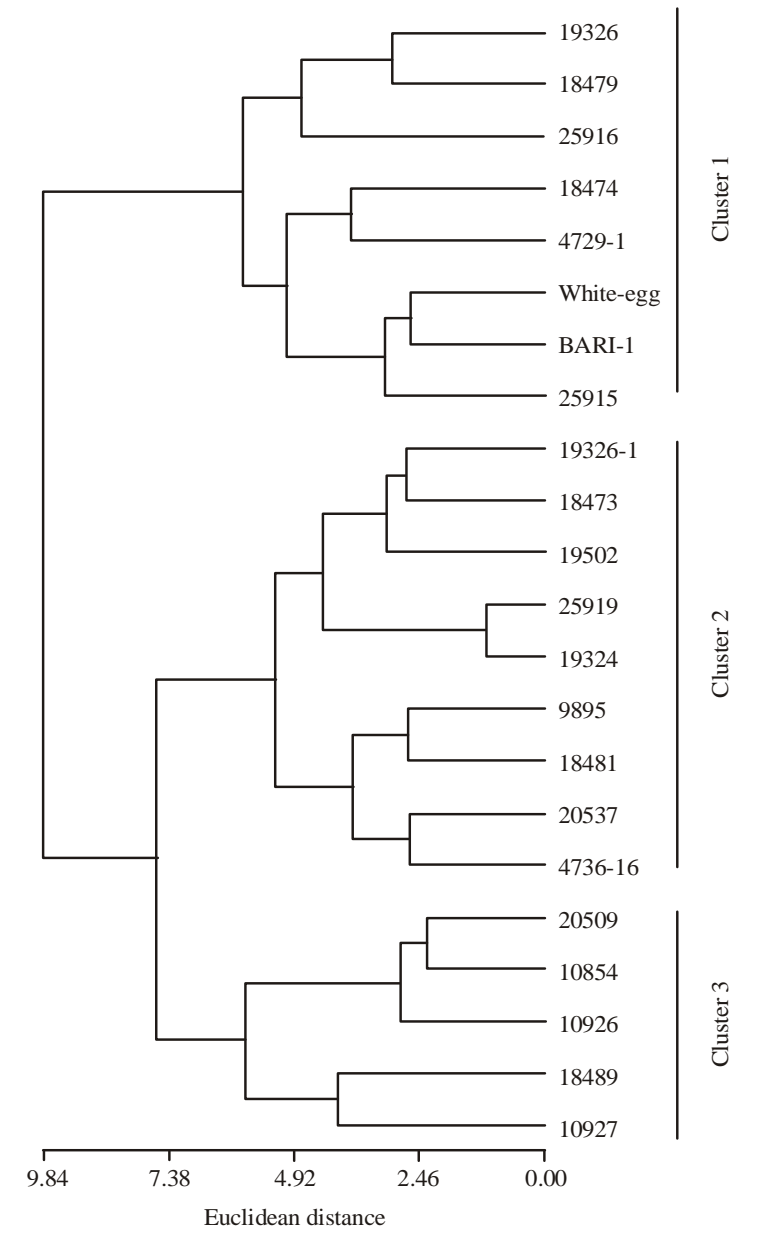

Fig. 1: Relationship among variable Solanum accessions reflected in cluster analysis

cluster 3 results are almost same, while cluster 2 shows early flowering as compared to cluster 1 and 3, while height of first inflorescence was maximum in cluster 1 , 
followed by cluster 2 and 3. Maximum flowers per axil were in cluster 1 and minimum in cluster 2 . As the productive/economic parameter taken under consideration in Eggplant production is its fruit length, fruit diameter and fruit weight, so genotypes in cluster-2 can be used to develop cultivars with maximum fruit size and fruit weight. It was recorded that there was no correspondence between the collection origin and material collected. Therefore grouping pattern in the dendrogram was regardless of their collection origin. The clustering of accessions in different groups may be useful to provide base for further crop improvement in Eggplant.

In the current study, all the characterized genotypes shows moderate to high variation, this represented its significance. Top priority should be given to selection based on marketable demand and could be taken under consideration while formulating selection indices in the improvement of Eggplant. On the basis of vegetative and reproductive characters, 19326 was found to be most promising genotype. Although the information generated from these genotypes could be used in breeding programs. In addition, it would be worthwhile to explore new Solanum genotypes by collecting, evaluating and conserving its local genotypes, wild species, landraces and exotic germplasm to develop strong and successful breeding programmes.

\section{REFERENCES}

Anonymous, 2010. Crop reporting services of provinces. Pakistan Bureau of Statistics, Government of Pakistan, Pakistan.

Anonymous, 2012. Economic research service. United States Department of Agriculture.

Chattopadhyay, A., S. Dutta and P. Hazra, 2011. Characterization of genetic resources and identification of selection indices of Brinjal (Solanum melongena L.) grown in Eastern India. Veg. Crops Res. Bull., 74: 39-49.

Daunay, M.C. and R.N. Lester, 1989. The usefulness of taxonomy for Solanaceae Breeders, with special reference to the genus Solanum and to Solanum melongena L. (Eggplant). Capsicum Newslett., 7: 1-10.

Furini, A. and J. Wunder, 2004. Analysis of eggplant (Solanum melongena)-related germplasm: Morphological and AFLP data contribute to phylogenetic interpretations and germplasm utilization. Theor. Applied Genet., 108: 197-208.
George, R.A., 1989. Vegetable Seed Production. In: The Role of Plant Breeders in Seed Industry Development, George, R.A. (Ed.). John Wiley and Sons, New York, USA., pp: 15.

Hazra, P., A. Rout, U. Roy, S. Nath and T. Roy et al., 2003. Characterization of brinjal (Solanum melongena L.) germplasm. Veg. Sci., 30: $145-149$.

Islam, M.S. and M.S. Uddin, 2009. Genetic variation and trait relationship in the exotic and local eggplant germplasm. Bangladesh J. Agric. Res., 34: 91-96.

Javed, H., A. Mohsin, M. Aslam, M. Naeem, M. Amjad and T. Mahmood, 2011. Relationship between morphological characters of different Aubergine cultivars and fruit infestation by Leucinodes orbonalis Guenee. Pak. J. Bot., 43: 2023-2028.

Kumar, R., S.S. Gupta, N. Singh and A. Chandra, 2000. Evaluation of eggplant (Solanum melongena L.) germplasm under Sub-tropical condition. Capsicum Eggplant Newslett., 19: 115-118.

Lester, R.N. and S.M.Z. Hassan, 1991. Origin and Domestication of the Brinjal Eggplant, Solanum melongena, from S. incanum, in Africa and Asia. In: Solanaceae III: Taxonomy, Chemistry, Evolution, Hawkes, J.G., R.N. Lester, M. Nee and R.N. Estrada (Eds.). The Royal Botanic Gardens, Kew, Richmond, UK., ISBN-13: 9780947643317, pp: 369-387.

Malik, M.N., 1994. Vegetable Crops. In: Horticulture, Malik, M.N. and E. Bashir (Eds.). National Book Foundation, Islamabad.

Rodriguez-Burruezo, A., J. Prohens and F. Nuez, 2008. Performance of hybrids between local varieties of eggplant (Solanum melongena) and its relation to the mean of parents and to morphological and genetic distances among parents. Eur. J. Horticult. Sci., 73: 76-83.

Rohlf, F.J., 2000. NTSYS-pc: Numerical Taxonomy and Multivariate Analysis System. Version 2.1, Exeter Software Inc., New York, USA.

Sekara, A., S. Cebula and E. Kunicki, 2007. Cultivated eggplants-origin, breeding objectives and genetic resources, a review. Folia Horticult., 19: 97-114.

Upadhyaya, H.D., C.L.L. Gowda and D.V.S.S.R. Sastry, 2008. Plant genetic resources management: Collection, characterization, conservation and utilization. J. SAT Agric. Res., 6: 1-16. 